\title{
Sentimento de Gratidão na Infância: Algumas Considerações Teóricas
}

\author{
Feeling of Gratitude During Childhood: \\ Some Theoretical Considerations \\ Sentimiento de Gratitud en la Niñez: \\ Algunas Consideraciones Teóricas
}

Paula Grazziotin

Silveira Rava

Universidade Federal

do Rio Grande do Sul

http://dx.doi.org/10.1590/1982-3703000212013
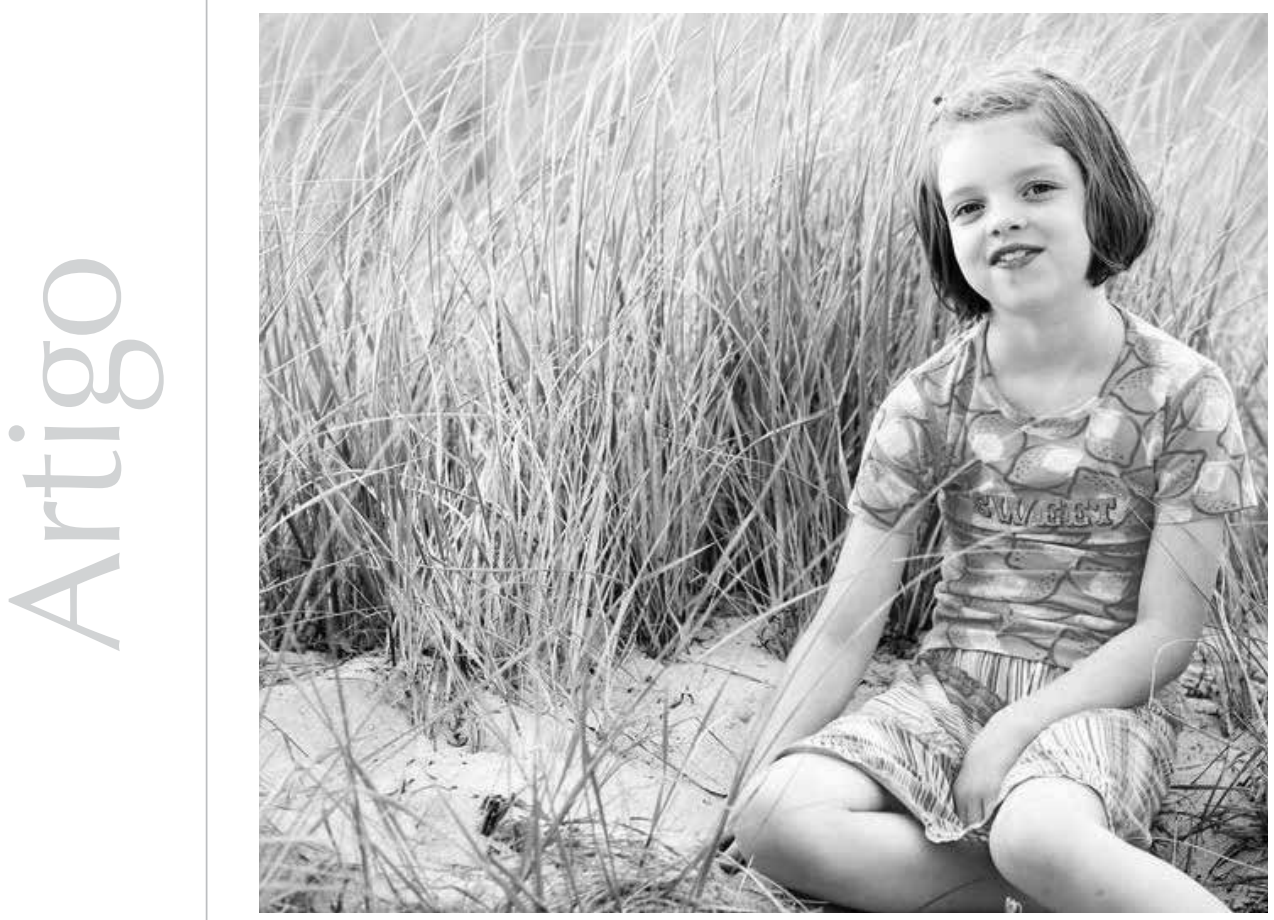
Resumo: O objetivo deste estudo é apresentar uma discussão teórica sobre o tema da gratidão. Inicialmente, define-se como se entende a gratidão neste trabalho. Prossegue-se versando sobre o que se sabe sobre a gratidão na infância. Por último, tem-se uma revisão de alguns resultados de estudos recentes, enfocando especialmente aqueles que versam sobre a distinção entre gratidão e obrigação. A gratidão tem sido estudada pelos psicólogos, mas as pesquisas empíricas enfocando o desenvolvimento desse sentimento ao longo da infância ainda são escassas. A relação entre gratidão e sentimento de obrigatoriedade também necessita de elucidação. Pode-se pensar que estudar como a gratidão se desenvolve na infância pode servir para a implementação de programas de intervenção com crianças a partir de estratégias que busquem potencializar esse sentimento em indivíduos que estão em fase precoce de desenvolvimento.

Palavras-chave: Gratidão. Infância. Desenvolvimento infantil. Moral.

Abstract: The objective of this study is to present a theoretical discussion on the subject of gratitude. Initially, we define how to understand gratitude in this work. It then goes on to what is known about gratitude in childhood. Finally, there is a review of some results of recent studies, focusing especially those that deal with the distinction between gratitude and indebtedness. Gratitude has been studied by psychologists, but empirical research focusing on the development of this feeling throughout childhood still is scarce. The relationship between gratitude and a sense of obligation also requires elucidation. One might think that studying how gratitude develops in childhood may serve to implement intervention programs with children based on strategies that seek to enhance this feeling in individuals who are at an early stage of development. Keywords: Gratitude. Childhood. Childhood development. Morals.

Resumen: El objetivo de este estudio es presentar una discusión teórica acerca del tema de la gratitud. Inicialmente, se define como se entiende la gratitud en este trabajo. Posteriormente, trata acerca de lo que se sabe sobre la gratitud en la niñez. Por último, se tiene una revisión de algunos resultados de estudios recientes, enfocando especialmente aquellos que tratan sobre la distinción entre gratitud y obligación. La gratitud ha sido estudiada por los psicólogos, pero las investigaciones empíricas que enfocan el desarrollo de ese sentimiento a lo largo de la niñez todavía son escasas. La relación entre gratitud y sentimiento de obligatoriedad también necesita elucidación. Se puede pensar que estudiar cómo la gratitud se desarrolla en la niñez puede servir para la implementación de programas de intervención con niños a partir de estrategias que busquen potenciar ese sentimiento en individuos que se encuentra en una etapa precoz de desarrollo. Palabras clave: Gratitud. Niñez. Desarrollo infantil. Moral.

Este trabalho inicia diante de uma diversidade de conceitos sobre gratidão. Na Psicologia, a gratidão é concebida tanto como virtude moral (e.g., La Taille, 2000, 2001) quanto como um sentimento moral (e.g., Baumgarten-Tramer, 1938; Bonnie \& de Waal, 2004; Piaget, 1954/2005, 1965/1973a), ou ainda emoção (e.g., Frederickson, 2004; Frederickson, Tugade, Waugh \& Larkin, 2003) e afeto (e.g., McCullough, Kilpatrick, Emmons \& Larson, 2001).

A maioria dos estudos recentes sobre a gratidão tem sido realizada na perspectiva da Psicologia positiva, a qual visa estudar os recursos adaptativos do ser humano em vez dos aspectos psicopatológicos (Mastern, 2001; Seligman \& Csikszentmihalyi, 2000) e tem abordado temas tais como bem-estar, satisfação, esperança, otimismo, felicidade, gratidão e perdão. Esses estudos mostram que a gratidão está associada ao bem-estar subjetivo, religiosidade, espiritualidade, felicidade (Bono \& McCullough, 2006; Watkins, Woodward, Stone \& Kolts, 2003) e satisfação vital (McCullough, Tsang \& Emmons, 2004). A gratidão também pode motivar a confiança e interdependência nos relacionamentos (Cohen, 2006). Segundo Kashdan e Breen (2007), valores materialistas estão positivamente associados com emoções negativas, como a depressão e a ansiedade social, e inversamente associados com a autonomia, competência, gratidão e a presença de sentido de vida. Além disso, Bono e McCullough (2006) sugerem que gratidão também pode oferecer proteção contra transtornos psiquiátricos. Em outras palavras, os estudos da Psicologia positiva têm chamado a atenção para a importância da gratidão para a felicidade das pessoas. 
No campo da

Psicologia do desenvolvimento, tem-se a hipótese de Piaget

(1954/2005) de que a gratidão na criança mais jovem é diferente da gratidão na criança mais velha.
Conforme observaram Freitas, Pieta e Tudge (2011), esses estudos não apenas têm contribuído para que se compreenda a relevância da gratidão na vida humana, mas também têm evidenciado lacunas no conhecimento. Uma delas diz respeito ao desenvolvimento da gratidão. Como ressaltaram Froh, Sefick e Emmons (2008), o percurso do desenvolvimento da gratidão precisa ainda ser investigado. Outra questão que ainda não está suficientemente elucidada, de acordo com Anderson (2005), é a distinção entre gratidão e obrigação de retribuir.

No campo da Psicologia do desenvolvimento, tem-se a hipótese de Piaget (1954/2005) de que a gratidão na criança mais jovem é diferente da gratidão na criança mais velha. Piaget formulou essa hipótese, mas não a investigou empiricamente. Antes mesmo de Piaget ter levantado essa hipótese, Baumgarten-Tramer (1938) realizou um estudo empírico com crianças e adolescentes, no qual constatou diferentes formas de expressão da gratidão, as quais variavam de acordo com a idade dos participantes.

Assim, observa-se que, embora se tenha levantado a hipótese de que haveria um desenvolvimento da gratidão e haja estudos que indicam que a gratidão faz parte da vida de crianças e adolescentes, não se sabe ainda qual é o percurso desse desenvolvimento. O objetivo deste estudo é apresentar uma discussão teórica sobre o tema da gratidão. Inicialmente, define-se como se entende a gratidão neste trabalho enfocando-se as semelhanças e diferenças entre os modelos teóricos utilizados para a conceitualização da gratidão. Prossegue-se versando sobre o que se sabe sobre a gratidão na infância, pois as evidências mostram que, em virtude de seus benefícios, esse é um sentimento que deve ser cultivado nas crianças. Por último, em função da controvérsia existente na literatura sobre a relação entre os sentimentos de gratidão e obrigação, tem-se uma revisão de alguns resultados de estudos recentes, enfocando especialmente aqueles que versam sobre a distinção entre gratidão e obrigação. A elucidação sobre o desenvolvimento da gratidão na infância pode contribuir na elaboração de programas de intervenção em educação moral que fomentem o sentimento de gratidão nas crianças.

\section{Conceitualização da gratidão}

Para explicar as trocas sociais, Piaget (1965/1973a) parte da ideia de que toda ação ou reação de uma pessoa terá repercussão nas demais, que pode ser considerada satisfatória, prejudicial ou indiferente. Ele afirma que "cada ação provocará, pois, por parte dos outros indivíduos uma ação de volta" (p. 119). Segundo Piaget (1965/1973a), três são as possibilidades quando um sujeito hipotético A presta um serviço a $B$, admitindo-se que o resultado da ação de $A$ é um valor para B: (a) B prestará um serviço em troca a A, (b) $B$ não presta um serviço imediatamente, mas se contenta em valorizar $A$ e (c) $B$ não presta nenhum serviço a $A$, nem o valoriza. Conforme afirma Piaget (1965/1973a), "neste caso é B que é desvalorizado por A, sendo considerado ingrato ou injusto" (p. 20). Piaget demonstra que em qualquer uma dessas três possibilidades ocorre troca de valores. Como isso acontece? Em primeiro lugar, o serviço prestado por A a B é uma "renúncia atual" para A e uma "satisfação (ou benefício) atual" para B. Em segundo lugar, a valorização de A por B constitui uma "satisfação virtual" de A. Em terceiro lugar, a valorização de A por B constitui para B um "compromisso, uma obrigação, uma renúncia virtual" e é por isso que B permanece "agradecido" mesmo depois de ter prestado um serviço de troca a A. Percebe-se que Piaget refere que nas trocas sociais pode ocorrer a valorização apenas da ação ou benefício recebido e, além disso, pode ocorrer também a valorização do benfeitor. É justamente dessa valorização do benfeitor (aquele que prestou o serviço) que 
decorre uma "dívida de reconhecimento" ( $\mathrm{p}$. 121). Dessa forma, pode-se constatar que nas trocas sociais podem ocorrer diversas doses de valorização recíproca. Isso se aplica no caso da gratidão, pois se pode valorizar apenas o objeto ou benefício recebido, desconsiderando a pessoa que motivou essa satisfação, ou, em um nível mais complexo, pode-se valorizar não apenas o benefício recebido, mas, principalmente, o benfeitor.

Nota-se que Piaget (1965/1973a) chama a atenção para essa importante distinção entre a valorização da ação ou serviço e a valorização da pessoa ou indivíduo. Ele afirma que respeitar alguém significa atribuir-lhe um valor. Porém, pode-se atribuir um valor a uma de suas ações, sem necessariamente valorizar essa pessoa como indivíduo. Nesse modelo proposto por Piaget (1965/1973a) para explicar a troca social, encontra-se a ideia de que, na gratidão, o beneficiário valoriza não apenas a ação do benfeitor, mas o próprio benfeitor. É dessa valorização positiva do próprio benfeitor que decorre o sentimento de uma dívida psicológica do beneficiário e uma obrigação de retribuir-lhe o favor.

Assim como no modelo proposto por Piaget (1965/1973a), o modelo de Bonnie e de Waal (2004), a partir da perspectiva etológica, também ilustra, de maneira semelhante, a explicação dos mecanismos da gratidão. Quando um indivíduo recebe uma ação generosa de outro, essa ação dá origem a um bom sentimento. O beneficiário associa esse sentimento ao benfeitor. Além disso, ele reconhece os custos da ação e atribui boas intenções ao benfeitor. Assim, o beneficiário torna-se grato não apenas pela ação recebida, mas também ao próprio benfeitor. O beneficiário, então, sente uma dívida em relação ao benfeitor e uma obrigação de retribuir o favor. Finalmente, o beneficiário retribui o favor ao benfeitor e o ciclo continua, porque o benfeitor inicial (agora beneficiário) sente-se bem.
Esse seria o ciclo completo da troca recíproca que conduziria ao sentimento de gratidão, $\mathrm{o}$ qual Bonnie e de Waal (2004) denominaram "Ciclo 3". Os autores afirmam que "os humanos frequentemente, mas nem sempre, seguem o ciclo completo, que é denominado como o terceiro" (p. 223). Esse ciclo, porém, nem sempre está presente em uma troca de serviços. Muitas vezes, a retribuição de um favor é realizada quase que automaticamente, sem que qualquer tipo de sentimento esteja envolvido ("Ciclo 1"). Outra possibilidade seria a de que um sentimento positivo seja despertado no beneficiário, sem que esse sentimento leve a uma avaliação dos custos da ação para o benfeitor ou de suas intenções ("Ciclo 2"). Nessa situação, pode-se gerar uma atitude positiva do beneficiário em relação ao benfeitor, mas não haveria uma valorização positiva do próprio benfeitor e, consequentemente, não surgiria o sentimento de obrigatoriedade de retribuir o favor.

Pode-se pensar na gratidão por meio da comparação entre esses dois modelos, a partir de suas semelhanças e diferenças. Uma das semelhanças entre esses dois modelos é que ambos preveem múltiplas possibilidades de trocas. Piaget fala de três possibilidades quando um sujeito hipotético A presta um serviço a um sujeito B; Bonnie e de Waal (2004) descrevem três ciclos ou níveis em que essas trocas ocorrem. Outra semelhança é que esses dois modelos propõem que a gratidão é decorrente de uma valorização do benfeitor e não apenas de sua ação. Porém, o modelo de Bonnie e de Waal propõe a existência de níveis de complexidade em que essas trocas se realizam nas diferentes espécies, e esses níveis não estão presentes no modelo de Piaget (1965/1973a). Ao partir da aproximação entre esses dois modelos, pode-se pensar que o modelo de Bonnie e de Waal poderia servir também para explicar o desenvolvimento da gratidão na infância, ou seja, os ciclos mais elementares (Ciclos 1 e 2) apareceriam antes no desenvolvimento da criança que o Ciclo 3 (Freitas et al., 2009a). 
Além de Piaget (1965/1973a) e de Bonnie e de Waal (2004), Godbout (1992) também trata da gratidão contextualizando-a em um ciclo.
Embora não tenha testado empiricamente, Piaget (1954/2005) levantou a hipótese de que a gratidão nas crianças menores seria diferente de nas mais velhas. Ele afirma que "a gratidão seria um sentimento frágil na criança pequena, mas que logo se estabilizaria graças à conservação dos valores e à obrigação moral (autônoma)" (p. 89). Essa importância dada à conservação de valores para o fortalecimento do sentimento de gratidão também é sustentada pelo antropólogo Godbout (1992) ao definir a retribuição como o ato de "religar um gesto a outro que ocorreu num passado próximo ou longínquo" (p. 138).

Além de Piaget (1965/1973a) e de Bonnie e de Waal (2004), Godbout (1992) também trata da gratidão contextualizando-a em um ciclo. Nessa perspectiva, a gratidão emergiria em um ciclo dar-receber-retribuir (Godbout, 1992). O referido autor salienta que esses "três momentos do ciclo geralmente se confundem do ponto de vista do ator, pois dar é retribuir, e vice-versa" (p. 137). Pode-se constatar o caráter da inseparabilidade entre esses três aspectos da gratidão: o dom ou dádiva, a reação diante do recebimento do benefício e a retribuição.

Cabe salientar que dois aspectos da gratidão - a reação diante do benefício e a retribuição - também estão presentes nas ideias de outros teóricos que estudaram essa temática. Conforme os estudos pioneiros de Baumgarten-Tramer (1938) e de Westermarck (1908/1928), Freitas et al. (2009a) afirmam que a gratidão foi descrita como um sentimento reativo (BaumgartenTramer, 1938) ou retributivo (Westermarck, 1908/1928) de um indivíduo a uma ação generosa de outro. Assim, o aspecto reativo pode ser entendido como o sentimento do beneficiário frente a uma ação generosa do benfeitor e o aspecto retributivo seria a ação que leva o beneficiário a retribuir o benefício recebido. Essas duas características da gratidão presentes em BaumgartenTramer (1938) e Westermarck (1908/1928) também estão de acordo com o pensamento de autores contemporâneos que seguem ressaltando esses aspectos da reação diante de um benefício recebido e da retribuição em suas ideias sobre a gratidão (Bonnie \& de Waal, 2004; McCullough et al., 2001).

Apesar do sentimento de gratidão parecer fazer parte de nosso arcabouço genético (Bonnie \& de Waal, 2004), ele "não emerge espontaneamente em recém-nascidos" (Emmons \& Shelton, 2002, p. 468). Em outras palavras, a gratidão não é inata, portanto é possível desenvolvê-la. Ainda que a trajetória do desenvolvimento da gratidão seja uma questão a ser investigada (Froh et al., 2008), alguns estudos indicam que as crianças são capazes de vivenciar, compreender e expressar gratidão, conforme será mostrado na sessão a seguir.

\section{Estudos sobre o desenvolvimento da gratidão na infância}

A maioria dos estudos recentes sobre a gratidão foi realizada com adultos (Freitas et al., 2011; Froh, 2010; Pieta \& Freitas, 2009). Estudos na área da infância revelam que a gratidão está associada a crianças e adolescentes menos ansiosos e mais felizes (Kasser, 2005) e que demonstram mais sentimentos positivos sobre a escola, os amigos e os professores (Bono \& Froh, 2009; Froh et al., 2008).

Baumgarten-Tramer (1938) foi uma das pioneiras em estudos empíricos com crianças e adolescentes (7 a 15 anos). Ela constatou, nas respostas dos participantes, quatro formas de expressar gratidão: verbal, concreta, conectiva e finalística. As frequências desses diferentes tipos de gratidão variaram de acordo com a idade dos participantes, 
sugerindo que essas diferentes formas de expressar gratidão surgiriam em diferentes momentos do desenvolvimento. A gratidão verbal pode reproduzir um aprendizado da criança, sem denotar necessariamente um sentimento de gratidão. No entanto, para Baumgarten-Tramer, a gratidão verbal poderia também ser utilizada quando a criança sente gratidão, mas não sabe expressar o que sente. A gratidão verbal foi encontrada com a mesma frequência até os 14 anos (em média, entre $30 \%$ e $40 \%$ das respostas). A gratidão concreta aparece quando a criança retribui com algo que tem valor para ela e não necessariamente para o benfeitor. A gratidão conectiva corresponde a uma ligação entre beneficiário e benfeitor, evidenciada em respostas do tipo "vou lembrar da pessoa que me auxiliou para o resto da vida". Este tipo de gratidão apareceu de forma significativa em crianças acima de 11 anos, sendo muito frequente nas de 12 anos (60\%). A gratidão finalística, por sua vez, refere-se a uma meta ou objetivo por parte do beneficiário. Exemplo deste tipo de gratidão é o caso em que a pessoa promete ser assídua e esforçada como forma de agradecimento àquele que lhe ofereceu um emprego. Para essa pesquisadora, a gratidão tem quatro componentes: alegria, benevolência para com o benfeitor, um desejo de retribuir e um sentimento de obrigação em retribuir.

Até recentemente, a hipótese de BaumgartenTramer (1938) não havia sido verificada, embora fosse a única tentativa científica conhecida de buscar especificamente elucidar o desenvolvimento da gratidão (Froh, Miller \& Snyder, 2007). Sendo assim, Freitas et al. (2011) realizaram um estudo sobre a expressão da gratidão com crianças e adolescentes de Porto Alegre. Como resultados obtidos é possível citar a existência de uma diferença entre a expressão da gratidão e a compreensão integral desse sentimento pelas crianças. Sendo assim, algumas crianças já utilizam formas convencionais de expressar gratidão mesmo antes de compreendêla. Esses resultados corroboram o estudo empírico de Baumgarten-Tramer (1938), no qual a autora cita a gratidão verbal, em que a criança diz "obrigado", parecendo reproduzir um termo aprendido com pais e professores, sem ser necessariamente acompanhada de um sentimento de gratidão.

As pesquisas sugerem que as crianças expressam e compreendem a gratidão durante a infância, mas ainda não está claro a partir de que momento isso ocorre (BaumgartenTramer, 1938; Becker \& Smenner, 1986; Gleason \& Weintraub, 1976; Graham, 1988; Graham \& Barker, 1990; Harris, Olthof, Meerum Terwogt \& Hardman, 1987; Russell \& Paris, 1994). Nesse sentido, Gleason e Weintraub (1976) evidenciaram que poucas crianças (21\%) com menos de 6 anos agradecem a um adulto que the deu uma bala, enquanto mais de $80 \%$ das crianças de 10 anos agradecem na mesma situação. Isso ocorre apesar dos frequentes incentivos de pais e professores para que as crianças agradeçam quando recebem um presente ou algum tipo de ajuda. Por outro lado, Becker e Smenner (1986) verificaram que crianças pré-escolares (entre 3 e 4 anos) agradecem mais a um adulto que a uma outra criança quando recebem um presente. Todavia, deve-se ressaltar que agradecer não significa necessariamente sentir gratidão, pois esse agradecimento pode apenas representar uma forma de polidez.

Na gênese da moralidade, a polidez é um indício de que a pessoa provavelmente comporta-se bem, que não transgride as regras e mostra-se solidária, generosa e corajosa. A polidez ocupa um lugar relevante na gênese da moralidade, pois "pertence ao conjunto de valores e regras com os quais a criança penetra no universo moral e sobre os quais reconstrói esse universo em direção à autonomia" (La Taille, 2001, p. 16). A polidez também é definida como formas de 
...pode-se pensar que a gratidão se relaciona, de alguma forma, com a polidez, ou seja, uma maneira polida ou educada de responder a um ato generoso recebido pode indicar que talvez o indivíduo esteja expressando gratidão em um de seus níveis mais elementares (BaumgartenTramer, 1938). falar e/ou agir convencionadas nas relações sociais - as "boas maneiras". Colston (2002) também salienta a importância da expressão da gratidão como forma de gentileza, polidez e indicação de respeito e estima pelo outro. Assim sendo, pode-se pensar que a gratidão se relaciona, de alguma forma, com a polidez, ou seja, uma maneira polida ou educada de responder a um ato generoso recebido pode indicar que talvez o indivíduo esteja expressando gratidão em um de seus níveis mais elementares (Baumgarten-Tramer, 1938). Entretanto, deve-se salientar que o agradecimento verbal, que é uma forma de polidez, muitas vezes não vem acompanhado do sentimento genuíno de gratidão, pois agradecemos, muitas vezes, apenas por uma questão de polidez e não porque nos sentimos verdadeiramente gratos (Freitas, Silveira \& Pieta, 2009b). Bono e Froh (2009) dizem que a distinção entre a polidez (por exemplo, dizer obrigado) e um genuíno sentimento de gratidão é um dos maiores desafios para os pesquisadores que realizam estudos com crianças.

No que se refere à compreensão do sentimento de gratidão pelas crianças, não existe consenso: alguns autores acreditam que essa compreensão não ocorreria antes dos 7 anos de idade; outros sugerem que desde os 4 anos as crianças têm alguma ideia sobre gratidão. McAdams e Bauer (2004) propõem que a gratidão somente seria possível em crianças ao redor do quarto ano de vida, quando elas começariam a ter uma teoria da mente, isto é, quando passam a entender que outras pessoas, assim como elas mesmas, são seres que têm intenção. Por outro lado, um estudo recente com 228 crianças norte-americanas de 5 anos que testou a hipótese de que a teoria da mente seria uma condição necessária para a gratidão não encontrou suficiente suporte empírico (Freitas, O’Brien, Nelson \& Stuart, 2012).

Harris et al. (1987) realizaram um estudo com crianças inglesas e holandesas (entre 5 e 14 anos de idade) e constataram que as crianças seriam capazes de entender situações que provocam sentimento de gratidão apenas a partir dos 7 anos. Russell e Paris (1994) fizeram uma pesquisa com crianças canadenses de 4 a 7 anos de idade e constataram que as crianças reconhecem a gratidão como um sentimento prazeroso a partir dos 4 anos, embora não saibam ainda descrever uma situação em que esse sentimento ocorre. Esses autores propuseram que a aquisição da compreensão de sentimentos complexos como a gratidão ocorreria de forma gradual ao longo da infância, de acordo com, no mínimo, três níveis. O primeiro se refere à ausência de conhecimento, o segundo trata do conhecimento do prazer ou desprazer associado ao sentimento e o último seria o conhecimento de situações específicas que provocam o sentimento.

A relação entre o sentimento de gratidão e a intencionalidade (McAdams \& Bauer, 2004) da ação do benfeitor foi outro aspecto estudado e também parece desenvolver-se durante a infância. Antes dos 7-8 anos, as crianças tendem a levar em conta apenas o benefício recebido. Graham (1988) apresentou a crianças de diferentes idades (5-6 anos, 7-8 anos e 10-11 anos) uma cena na qual uma criança é escolhida para participar de um time, sendo que: (a) foi solicitado ao capitão do time escolher a referida criança ou (b) não foi solicitado ao capitão do time escolher especificamente essa criança. Embora as crianças de todas as idades tenham compreendido que, na primeira situação, o benefício recebido pela personagem não dependia do capitão do time, as crianças pequenas acreditavam que a personagem se sentiria igualmente grata, enquanto as crianças maiores (8 anos e 10-11 anos) esperavam que a personagem sentiria mais gratidão quando o capitão do time a havia voluntariamente escolhido. Graham e Barker (1990) apresentaram, em outro estudo, 
um vídeo para 90 crianças de diferentes faixas etárias (4-5 anos, 7-8 anos e 11-12 anos), no qual, durante uma prova de matemática, uma professora olha a prova de um estudante e segue adiante; a seguir, ela olha a prova de um segundo estudante e o ajuda, sem que ele tivesse solicitado a sua ajuda. Ambos os estudantes são igualmente bem sucedidos na prova. Todas as crianças consideraram que o estudante que recebeu ajuda sentiria mais gratidão que aquele que não recebeu ajuda da professora. No entanto, o fato de que as crianças atribuíram alguma gratidão ao estudante que não foi ajudado sugere que resultados positivos podem suscitar esse sentimento, independentemente da ação intencional de outrem.

Em estudo empírico, La Taille (1998) apresentou um dilema em que uma criança esquece o lanche e fica com fome, então sua colega reparte seu lanche com ela. Como resultados, esse autor encontrou que algumas crianças julgaram que o melhor seria retribuir um favor recebido; porém, quando foram tentar justificar sua resposta, passaram a pensar que seria melhor nunca esquecer o que a amiga (no caso benfeitora) fez. Observase, aqui, o importante papel da conservação de valores na gratidão. De acordo com os estudos da epistemologia genética de Piaget (1972/1983), a conservação resulta de uma operação intelectual que só se constituiria no estágio operatório concreto do desenvolvimento cognitivo da criança. Vê-se, aqui, mais um exemplo ilustrativo do paralelismo entre o desenvolvimento afetivo e cognitivo na teoria piagetiana.

Durante a adolescência, é esperado que a gratidão se desenvolva em níveis mais complexos, pois o autoentendimento tornase bastante enriquecido nessa etapa da vida. Dessa maneira, McAdams e Bauer (2004) partem de uma perspectiva desenvolvimentalinteracionista e formulam a hipótese de que a tendência de experienciar e de expressar gratidão se desenvolveria também ao longo da adolescência e, até mesmo, da vida adulta, em função de uma série complexa de fatores pessoais e ambientais.

Nota-se que muitas questões ainda permanecem em aberto no que se refere à aquisição, por parte das crianças, da noção de gratidão e também ao aspecto retributivo da gratidão. Por exemplo, não se sabe ao certo se as crianças julgam necessária a retribuição de uma benesse ou favor recebido e se essa necessidade de retribuição se modifica, sendo o benfeitor um adulto ou uma criança, ou, ainda, se é uma pessoa conhecida (um familiar, por exemplo) ou um desconhecido.

Uma forma de buscar esclarecimento a respeito das questões acima mencionadas é tentar compreender a gratidão como parte do processo de construção da moralidade humana a partir da teoria construtivista, a qual entende que o sentimento de obrigatoriedade se transforma à medida que o ser humano evolui de uma moral heterônoma para uma moral autônoma. A seguir, serão descritos estudos que relacionam gratidão e sentimento de obrigatoriedade.

\section{Gratidão e sentimento de obrigatoriedade}

Vários autores (Baumgarten-Tramer, 1938; Bonnie \& de Waal, 2004; Komter, 2004; Piaget, 1941/1973b) afirmam que o sentimento de gratidão implica uma dívida psicológica para com o benfeitor e que dessa dívida decorre um sentimento de que se deve retribuir o favor. De acordo com McConnell (1993), é a natureza gratuita da ação generosa do benfeitor que a torna digna de gratidão. "Isto significa, portanto, que o benefício foi dado livremente (...) e a retribuição não é requerida" (p. 23). Ora, se é necessário que o benefício tenha sido dado livre (sem o intuito de colocar o beneficiário 
em dívida) e gratuitamente (sem retribuição requerida), por que o beneficiário sente que deve retribuir? Conforme observaram Castro, Rava, Hoefelmann, Pieta e Freitas (2011), "frequentemente sentida como obrigatória, a retribuição tem intrigado os pesquisadores".

$\mathrm{Na}$ literatura recente sobre gratidão, encontram-se alguns estudos, conduzidos no campo da Psicologia positiva, que buscaram examinar as relações entre os sentimentos de gratidão e de obrigação de retribuir-se um favor. Goei e Boster (2005) realizaram dois experimentos com universitários para atingir três objetivos: (a) testar se gratidão e obrigação poderiam ser diferenciadas empiricamente, (b) testar o efeito potencial de um favor na gratidão e na obrigação e (c) testar os efeitos potenciais da gratidão e da obrigação no pós-cumprimento de um favor. Como resultados, eles obtiveram que uma diferença frequentemente assinalada entre os sentimentos de obrigação e de gratidão é que a primeira é um sentimento desprazeroso e causa mal-estar, enquanto a segunda seria um sentimento agradável, prazeroso e que proporcionaria bem-estar para o beneficiado. O sentimento de obrigação, nessa perspectiva, pode ser definido como um estado desconfortável e aversivo, que pode resultar em uma restrição comportamental devido à antecipação de sanções sociais negativas em razão da possível não obediência à norma de reciprocidade (Goei \& Boster, 2005). Nesse sentido, o sentimento de obrigação também pode acarretar em uma restrição de liberdade por parte do beneficiário, que normalmente se sente compelido a obedecer às solicitações futuras do benfeitor. Geralmente, os beneficiários de uma boa ação agem no sentido de reduzir esse mal-estar por meio da obediência aos pedidos e solicitações do benfeitor. Quando as pessoas se sentem obrigadas a retribuir um favor, elas, frequentemente, sentem-se chateadas e confusas sobre como responder nessa situação.
Watkins, Scheer, Ovnicek e Kolts (2006) conduziram dois experimentos correlacionando a variável endividamento com obrigação e gratidão. Eles utilizaram duas vinhetas para investigar modelos de respostas de gratidão e endividamento a partir do recebimento de benefícios. Os universitários que participaram desses estudos liam as histórias com a descrição do recebimento do benefício e eram questionados sobre como iriam responder a esse benefício a partir de uma série de escalas emocionais, incluindo gratidão e endividamento. Nessas histórias, eram manipuladas as expectativas de retorno do benfeitor associadas ao dom. Os resultados dessa pesquisa indicam que o endividamento esteve fortemente correlacionado à obrigação, evidenciando uma semelhança entre esses sentimentos. A gratidão não foi significativamente correlacionada com o endividamento, indicando uma distinção entre esses estados emocionais. Esses autores ressaltam, ainda, que a gratidão foi associada com amplas tendências de pensamento e ação pró-sociais e pareceu inibir tendências antissociais. A resposta de gratidão foi mais fortemente associada a inclinações para o altruísmo do que para o endividamento e os sentimentos de obrigação.

Watkins et al. (2006) sugerem, também, que uma importante diferença entre o endividamento e a gratidão talvez seja que o endividamento é uma "emoção de troca" enquanto que a gratidão não é. Todavia, às vezes, ocorre um tipo de reciprocidade, que é motivada pela gratidão, mas os estudos sugerem que, quando o beneficiado retribui um favor, ele não percebe seu ato em termos de troca. Nesse sentido, o filósofo ComteSponville (2007) faz um alerta para que não se confunda gratidão com retribuição de cortesias. La Taille (1998) também refere que gratidão não é mera retribuição. "Ser grato a alguém pressupõe valorizar o que uma relação humana tem de singular e especial e reforçá-la" (La Taille, 2006, p. 61). 
Deve-se

evidenciar que

a expressão

"paradoxo

do altruísmo"

(Watkins et al.,

2006), conforme

colocado acima,

seria, por si só,

contraditória, pois

no ato altruísta tal

qual é entendido

neste estudo,

não se esperam

recompensas ou

reconhecimentos

de nenhuma

espécie.
Outra diferença apontada por Watkins et al. (2006), com base nos estudos de Heider (1958), é a de que, nas situações em que o benfeitor obriga o beneficiado a ser grato, o beneficiado deve experimentar menos gratidão. Segundo esses autores, isso ocorre porque a gratidão opera independentemente das pressões da obrigação (Goei \& Boster, 2005). Então, geralmente quando há um aumento nas expectativas externas para um retorno associado ao benefício, o sentimento de gratidão tende a declinar e a obrigação tende a aumentar. Quanto mais o benfeitor espera um retorno, maiores são as chances de o beneficiado apresentar atos de rejeição e evitação (Watkins et al., 2006). Quando os benefícios são esperados ou tidos como obrigatórios, como no caso das relações familiares, o sentimento de gratidão tende a ser experienciado com menor intensidade (Bono \& McCullough, 2006; McCullough et al., 2001). Isso é denominado, pelos autores, "paradoxo do altruísmo", ou seja, quando as expectativas de retribuição de favores aumentam por parte do benfeitor, o beneficiado está menos inclinado a ajudar (Watkins et al., 2006).

Cabe salientar que o comportamento altruísta é aquele que não vislumbra expectativas de retribuição. Assim, deve-se elucidar a diferença entre o altruísmo e o comportamento pró-social. Pode-se definir o comportamento pró-social como voluntário e intencional que resulta em benefício para o outro. O motivo é inespecífico e pode envolver razões altruístas ou egoístas como, por exemplo, ser recompensado ou reconhecido. O comportamento altruísta, em contraste, é definido como um subtipo de comportamento pró-social e refere-se a um comportamento voluntário, voltado ao benefício intencional ao outro e não executado pela expectativa de recebimento de recompensas externas ou para evitar punição. O comportamento pró-social motivado por razões altruístas está ligado conceitualmente à simpatia e à empatia (Eisenberg \& Miller, 1987). Geralmente, é difícil determinar os motivos das ações prósociais das pessoas e, por isso, muitas vezes é impossível distinguir o comportamento altruísta do comportamento pró-social não altruísta.

Deve-se evidenciar que a expressão "paradoxo do altruísmo" (Watkins et al., 2006), conforme colocado acima, seria, por si só, contraditória, pois no ato altruísta tal qual é entendido neste estudo, não se esperam recompensas ou reconhecimentos de nenhuma espécie. Sendo assim, ao se referir a um comportamento benevolente motivado por uma expectativa de retorno associado ao benefício concedido, provavelmente não seria o caso de batizá-lo de ato altruísta.

Assim, pode-se constatar que esses estudos empíricos (Goei \& Boster, 2005; Watkins et al., 2006) mostram que a gratidão e a obrigação são construtos diferentes. Um favor pode proporcionar sentimentos de obrigação ou de gratidão dependendo da relação e do vínculo que é gerado entre benfeitor e beneficiado. Um favor pode causar obrigação quando a afeição, simpatia ou estima pelo benfeitor é pequena e pode causar gratidão quando existe uma grande afeição pelo benfeitor. Sendo assim, os favores provenientes de um benfeitor considerado antipático provavelmente irão resultar em menor gratidão por parte do beneficiado (Heider, 1958).

As pessoas são mais propensas a sentir gratidão quando elas atribuem seu sucesso à ação de outra pessoa mais do que delas mesmas (Weiner, D. Russell \& Lerman, 1979; Zaleski, 1988). O indivíduo grato é aquele que sabe "ver no outro a causa de sua alegria" (Comte-Sponville, 2007, p. 148). Dessa forma, um favor intensifica a expressão da gratidão, especialmente quando o favor é proporcionado com um elevado custo para o 
benfeitor. Nesse caso, um favor muito custoso para o benfeitor cria uma obrigação maior de reciprocidade, pois a norma de reciprocidade requer a troca de serviços equivalentes (Goei \& Boster, 2005). A norma de reciprocidade, nesse caso, pode ser entendida como uma percepção cognitiva de que um deve restituir outra pessoa que lhe proporcionou assistência. Em algumas circunstâncias, a gratidão pode facilitar o comportamento prósocial de uma forma que uma norma social isolada de reações emocionais não consegue (Bartlett \& DeSteno, 2006). Todavia, às vezes, não é possível prestar um serviço equivalente como, por exemplo, se uma pessoa lhe salva a vida. McConnell (1993) propõe que não há necessidade de se retribuir com um bem equivalente, mas sim com algo que atenda a uma necessidade genuína de um benfeitor prévio.

Nota-se que a literatura recente revela a existência de estudos na área da Psicologia (Anderson, 2005; Goei \& Boster, 2005; Watkins et al., 2006) cujos resultados indicam diferenças entre os sentimentos de gratidão e obrigação. No entanto, a obrigatoriedade não está inteiramente ausente na gratidão, visto que a valorização do benfeitor, da qual ela emerge, leva a uma dívida psicológica e uma necessidade de retribuição (BaumgartenTramer, 1938; Bonnie \& de Waal, 2004; Komter, 2004; Piaget, 1941/1973b). Em outras palavras, o beneficiário sente que deve retribuir o favor, se possível, quando surgir uma oportunidade adequada (McConnell, 1993).

\section{Considerações finais}

Ao receber um benefício ou ação benevolente, um indivíduo hipotético pode experienciar sentimentos diversos. A compreensão da gratidão pelos modelos teóricos utilizados neste estudo (Bonnie \& de Waal, 2004; Piaget, 1965/1973a) consideram como fator desencadeante desse sentimento a satisfação do beneficiário a partir do recebimento de um benefício. Assim, entende-se que o ponto de partida para o desencadeamento do sentimento de gratidão seria o sentimento positivo decorrente de uma ação generosa. Porém, o simples fato de o beneficiário sentir-se bem, por si só, não é suficiente para explicar esse complexo sentimento que é a gratidão. Esse bom sentimento gerado pelo recebimento de um benefício pode estar relacionado à valorização do benefício, da ação ou do benfeitor. Nesse caso, Piaget (1965/1973a) chama a atenção para o fato de que na gratidão ocorre não apenas a valorização da ação, mas também a valorização do benfeitor. Pode-se pensar que o sentimento de gratidão, entendido a partir dessa perspectiva, levaria ao reconhecimento e à valorização do outro. Dessa forma, no contexto de troca de favores, é a partir do sentimento de dívida psicológica proveniente da valorização do benfeitor que decorre o sentimento de obrigatoriedade de se retribuir um favor recebido. Essa necessidade de se retribuir uma boa ação recebida pode nos dar indícios do papel da gratidão na constituição da moralidade.

Komter (2004) ressalta o papel da gratidão para a manutenção dos vínculos e do grupo social justamente porque esse sentimento evidencia o fato de que muitas vezes não é possível levar uma vida isolada e que o outro tem importância na vida de qualquer indivíduo. Em outras palavras, em uma sociedade cujos valores individualistas estão em voga, cultivar o sentimento de gratidão desde a infância pode ser relevante.

A partir da revisão de literatura realizada, foi possível observar que a gratidão tem sido estudada pelos psicólogos, mas que as pesquisas empíricas enfocando o desenvolvimento desse sentimento ao longo da infância ainda são escassas (Froh et al., 2007; Froh et al., 2008; Gordon, MusherEizenman, Holub \& Dalrymple, 2004). A 
relação entre gratidão e obrigação de retribuir o favor tem intrigado os pesquisadores vários autores falam na dívida psicológica da gratidão (Baumgarten-Tramer, 1938; Bonnie \& De Waal, 2004; Komter, 2004; Piaget, 1965/1973a), enquanto algumas pesquisas afirmam que se trata de dois estados emocionais distintos (Anderson, 2005; Goei \& Boster, 2005; Watkins et al., 2006). Todavia, a obrigatoriedade parece ser uma dimensão da gratidão, pois ela surge a partir da valorização do benfeitor e isso leva a uma dívida psicológica e uma exigência de retribuição. Em virtude do que foi acima mencionado, pode-se pensar que estudar como a gratidão se desenvolve na infância pode servir para a implementação de programas de intervenção com crianças a partir de estratégias que busquem potencializar esse sentimento em indivíduos que estão em fase precoce de desenvolvimento. 


\section{Paula Grazziotin Silveira Rava}

Doutora pelo Programa de Pós-Graduação em Psicologia da Universidade Federal do Rio Grande do Sul. Docente da Faculdade de Psicologia da Pontifícia Universidade Católica do Rio Grande do Sul, Porto Alegre - RS - Brasil. E-mail: paulagraz@yahoo.com

\section{Endereço para envio de correspondência:}

Rua Machado de Assis, 855/1206, Jardim Botânico. CEP: 90620-260. Porto Alegre, RS.

Recebido 30/11/2012, Aprovado 29/08/2013

\section{Referências}

Anderson, N. H. (2005). How sharper than a serpent's tooth. Journal of Social and Clinical Psychology, 24 (7), 1077-1080. doi: 10.1521/jscp.2005.24.7.1077

Bartlett, M. Y., \& DeSteno, D. (2006). Gratitude and prosocial behavior. Psychological Science, 17(4), 319-325. doi: $10.1111 / \mathrm{j} .1467-9280.2006 .01705 . x$

Baumgarten-Tramer, F. (1938). "Gratefulness" in children and young people. Journal of Genetic Psychology, 53(1), 53-66. doi: 10.1080/08856559.1938.10533797

Becker, J. A., \& Smenner, P. C. (1986). The spontaneous use of thank you by preschoolers as a function of sex, socioeconomic status, and listener status. Language in Society, 15(4), 537546. doi: : http://dx.doi.org/10.1017/S0047404500012008

Bonnie, K. E., \& de Waal, B. M. (2004). Primate social reciprocity and the origin of gratitude. In R. A. Emmons \& M. E. McCullough (Eds.), The psychology of gratitude (pp. 213-229). New York: Oxford University Press.

Bono, G., \& Froh, J. (2009). Gratitude in school: Benefits to students and Schools. In R. Gilman, E. S. Huebner, \& M. Furlong (Eds.), Handbook of Positive Psychology in schools (pp. 77-88). New York: Routledge.

Bono, G., \& McCullough, M. E. (2006). Positive responses to benefit and harm: Bringing forgiveness and gratitude into cognitive psychotherapy. Journal of Cognitive Psychotherapy: An international Quartely, 20(2), 147-158.

Castro, F. M. P., Rava, P. G. S., Hoefelmann, T. B., Pieta, M. A. M., \& Freitas, L. B. L. (2011). Deve-se retribuir? Gratidão e dívida simbólica na infância. Estudos de Psicologia (Natal), 16(1), 75-82. doi: http://dx.doi.org/10.1590/S1413294X2011000100010

Cohen, A. B. (2006). On gratitude. Social Justice Research, 19(2), 254-276. doi: 10.1007/s11211-006-0005-9

Colston, H. L. (2002). Pragmatic justifications for nonliteral gratitude acknowledgments: "Oh sure, anytime". Metaphor and Symbol, 17(3), 205-226. doi: 10.1207/ S15327868MS1703_3
Comte-Sponville, A. (2007). Pequeno tratado das grandes virtudes (E. Brandão, Trad.). São Paulo: Martins Fontes.

Eisenberg, N., \& Miller, P. A. (1987). The relationship of empathy to prosocial and related behaviors. Psychological Bulletin, 101(1), 91-119. doi: 10.1037/0033-2909.101.1.91

Emmons, R. A., \& Shelton, C. M. (2002). Gratitude and Positive Psychology. In C. R. Snyder, \& S. J. Lopez (Eds.), Handbook of Positive Psychology (pp. 459-471). New York: Oxford University Press.

Frederickson, B. L. (2004). Gratitude, like other positive emotions, broadens and builds. In R. A. Emmons \& M. E. McCullough (Eds.), The psychology of gratitude (pp. 145-166). New York: Oxford University Press.

Frederickson, B. L., Tugade, M. M., Waugh, C. E., \& Larkin, G. R. (2003). What good are positive emotions in crises? A prospective study of resilience and emotions following the terrorist attacks on the United States on September $11^{\text {th }}$, 2001. Journal of Personality and Social Psychology, 84(2), 365-376. doi: 10.1037/0022-3514.84.2.365

Freitas, L. B. L. (1999). Do mundo amoral à possibilidade de ação moral. Psicologia: Reflexão e Crítica, 12(2), 447-458. doi: http://dx.doi.org/10.1590/S0102-79721999000200013

Freitas, L. B. L., Silveira, P. G., \& Pieta, M. A. M. (2009a). Sentimento de gratidão em crianças de 5 a 12 anos. Psicologia em Estudo, 14(2), 243-250. doi: http://dx.doi.org/10.1590/ S1413-73722009000200004

Freitas, L. B. L., Silveira, P. G., \& Pieta, M. A. M. (2009b). Um estudo sobre o desenvolvimento da gratidão na infância. Revista Interamericana de Psicologia, 43(1), 22-29.

Freitas, L. B. L., Pieta, M. A. M., \& Tudge, J. R. H. (2011). Beyond politeness: The expression. Of gratitude in children and adolescents. Psicologia: Reflexão e Crítica, 24(4), 757-764. doi: http://dx.doi.org/10.1590/S0102-79722011000400016

Freitas, L. B. L, O'brien, M., Nelson, J. A. \& Marcovitch, S. A. (2012). Compreensão da gratidão e teoria da mente em crianças de 5 anos. Psicologia: Reflexão e Crítica., 25(2), 330-338. doi: http://dx.doi.org/10.1590/S010279722012000200015 
Froh, J. J. (2010, April). Teaching children how to think gratefully: Unveiling a new gratitude intervention for youth. Paper presented at the Conference on Human Development, New York City.

Froh, J. J., Miller, D. N., \& Snyder, S. (2007). Gratitude in children and adolescents: Development, assessment, and SchoolBased Intervention. School Psychology Forum: Research in Practice, 2(1), 1-13.

Froh, J. J., Sefick, W. J., \& Emmons, R. A. (2008). Counting blessings in early adolescents: An experimental study of gratitude and subjective well-being. Journal of School Psychology, 46, 213-233. doi: 10.1016/j.jsp.2007.03.005

Gleason, J. B., \& Weintraub, S. (1976). The acquisition of routines in child language. Language in Society, 5(2), 129-136. doi: http://dx.doi.org/10.1017/S0047404500006977

Godbout, J. T. (1992). O espírito da dádiva (J. P. Cabrera, Trad.). Lisboa: Instituto Piaget.

Goei, R., \& Boster, F. (2005). The roles of obligation and gratitude in explaining the effect of favors on compliance. Comunication Monografiphs, 72(3), 284-300. doi: 10.1080/03637750500206524

Gordon, A. K., Musher-Eizenman, D. R., Holub, S. C., \& Dalrymple, J. (2004). What are children thankful for? An archival analysis of gratitude before and after the attacks of September 11. Journal of Applied Developmental Psychology, 25(5), 541-553. doi: 10.1016/j.appdev.2004.08.004

Graham, S. (1988). Children's developing understanding of the motivational role of affect: An attributional analysis. Cognitive Development, 3(1), 71-88. doi: 10.1016/08852014(88)90031-7

Graham, S., \& Barker, G. P. (1990). The down side of help: An attributional-developmental analysis of helping behavior as a low-ability cue. Journal of Educational Psychology, 82(1), 7-14. doi: 10.1037/0022-0663.82.1.7

Harris, P. L., Olthof, T., Meerum Terwogt, M., \& Hardman, C. E. (1987). Children's knowledge of the situations that provoke emotion. International Journal of Behavioral Development, 10(3), 319-343. doi: 10.1177/016502548701000304

Heider, F. (1958). The psychology of interpersonal relations. New York: Wiley.

Kashdan, T. B., \& Breen, W. E. (2007). Materialism and diminished well-being: Experiential avoidance as a mediating mechanism. Journal of Social and Clinical Psychology, 26(5), 521-539. doi: 10.1521/jscp.2007.26.5.521

Kasser, T. (2005). Frugality, generosity, and materialism in children and adolescents. In K. A. Moore \& L. H. Lippman (Eds.), What do children need to flourish: Conceptualizing and measuring indicators of positive development (pp. 357-373). New York: Kluwer.

Komter, A. E. (2004). Gratitude and gift exchange. In R. A. Emmons \& M. E. McCoullough (Eds.), The psychology of gratitude (pp. 195-212). New York: Oxford University Press.

La Taille, Y. de (1998). As virtudes morais segundo as crianças (Relatório científico Fapesq). São Paulo: Universidade de São Paulo.
La Taille, Y. de (2000). Para um estudo psicológico das virtudes morais. Educação e Pesquisa, 26(2), 109-122. doi: http:// dx.doi.org/10.1590/S1517-97022000000200008

La Taille, Y. de (2001). Desenvolvimento moral: A polidez segundo as crianças. Cadernos de Pesquisa, 114, 89-119. doi: http://dx.doi.org/10.1590/S0100-15742001000300004

La Taille, Y. de (2006). Moral e ética: Dimensões intelectuais e afetivas. Porto Alegre: Artmed.

Mastern, A. S. (2001). Ordinary magic: Resilience process in development. American Psychologist, 56(3), 227-238.

McAdams, D. P., \& Bauer, J. J. (2004). Gratitude in modern life: Its manifestations and development. In R. A. Emmons \& M. E. McCoullough (Eds.), The psychology of gratitude (pp. 81-99). New York: Oxford University Press.

McConnell, T. (1993). Gratitude. Philadelphia: Temple University Press.

McCullough, M. E., Kilpatrick, S. D. Emmons, R. A, \& Larson, D. B. (2001). Is gratitude a moral affect? Psychological Bulletin, 127(2), 249-266. doi: 10.1037/0033-2909.127.2.249

McCullough, M. E., Tsang, J., \& Emmons, R. A. (2004). Gratitude in intermediate affective terrain: Links of grateful moods with individual differences and daily emotional experience. Journal of Personality and Social Psychology, 86(2), 295-309. doi: 10.1037/0022-3514.86.2.295

Piaget, J. (1973a). Estudos sociológicos (R. Di Piero, Trad.). Rio de Janeiro: Forense. (Trabalho original publicado em 1965).

Piaget, J. (1973b). Psicologia e pedagogia. Rio de Janeiro: Forense Universitária (Trabalho original publicado em 1941).

Piaget, J. (1983). Problemas de psicologia genética. Lisboa: Dom Quixote. (Trabalho original publicado em 1954).

Piaget, J. (2005). Inteligencia y afectividad. Buenos Aires: Aique Grupo Editor. (Trabalho original work published 1954).

Russell, J. A., \& Paris, F. A. (1994). Do children acquire concepts for complex emotions abruptly? International Journal of Behavior development, 17(2), 349-365. doi: 10.1177/016502549401700207

Seligman, M. E. P., \& Csikszentmihalyi, M. (2000). Positive Psychology: An introduction. American Psychologist, 55(1), 5-14. doi: 10.1037/0003-066X.55.1.5

Watkins, P. C., Scheer, J., Ovnicek, M., \& Kolts, R. (2006). The debt of gratitude: dissociating gratitude and indebtedness. Cognition and Emotion, 20(2), 217-241. doi: 10.1080/02699930500172291

Weiner, B., Russell, D., \& Lerman, D. (1979). The cognitionemotion process in achievement-related contexts. Journal of Personality and Social Psychology, 37(7), 1211-1220. doi:10.1037/0022-3514.37.7.1211

Westermarck, E. (1928). L'origine et le développement des idées morales. Paris: Payot (Trabalho original publicado em 1908).

Zaleski, Z. (1988). Attributions and emotions related to future goal attainment. Journal of Educational Psychology, 80(4), 563-568. doi:10.1037/0022-0663.80.4.563 